\title{
An Intensive Campaign-Based Intercomparison of Cloud Optical Depth from Ground and Satellite Instruments under Overcast Conditions
}

\author{
Alessandro Damiani ${ }^{1}$, Hitoshi Irie ${ }^{1}$, Tamio Takamura ${ }^{1}$, Rei Kudo ${ }^{2}$, Pradeep Khatri ${ }^{3}$, \\ Hironobu Iwabuchi ${ }^{3}$, Ryosuke Masuda ${ }^{3}$, and Takashi Nagao ${ }^{4}$ \\ ${ }^{1}$ Center for Environmental Remote Sensing, Chiba University, Chiba, Japan \\ ${ }^{2}$ Meteorological Research Institute, Japan Meteorological Agency, Tsukuba, Ibaraki, Japan \\ ${ }^{3}$ Center for Atmospheric and Oceanic Studies, Graduate School of Science, Tohoku University, Sendai, Japan \\ ${ }^{4}$ Atmosphere and Ocean Research Institute, The University of Tokyo, Kashiwa, Chiba, Japan
}

\begin{abstract}
We used observations recorded at Chiba University in November 2018 to examine the variability in cloud optical depth (COD) under overcast conditions. First, we conducted a careful evaluation of four COD datasets retrieved from three types of surface observations: i) zenith radiance recorded by two sky radiometers; ii) solar radiation data collected by a pyranometer; and iii) spatial distribution of radiance recorded using a sky camera system. Although the COD retrieved from the pyranometer (camera) slightly (moderately) overestimated the COD from zenith radiance, we found a satisfactory correlation among all surface estimates. This result suggests the efficacy of both pyranometer- and camera-based approaches and supports their broader use when dedicated cloud observations are not available. We then assessed satellite-based COD estimates retrieved from the recently launched Advanced Himawari Imager (AHI) aboard Himawari-8 (H-8) and Second-generation Global Imager (SGLI) on the Global Change Observation Mission for Climate (GCOM-C). Overall, we found good agreement between ground and satellite estimates; their correlation and root mean square error were virtually equivalent to values reported for co-located surface-based instruments. Nevertheless, the AHI-based COD was found to be slightly positively biased with respect to surface datasets.
\end{abstract}

(Citation: Damiani, A., H. Irie, T. Takamura, R. Kudo, P. Khatri, H. Iwabuchi, R. Masuda, and T. Nagao, 2019: An intensive campaign-based intercomparison of cloud optical depth from ground and satellite instruments under overcast conditions. SOLA, 15, 198-204, doi:10.2151/sola.2019-036.)

\section{Introduction}

Clouds' radiative effects strongly affect the Earth's climate, and clouds play a vital role in the energy balance of our planet (Wild et al. 2005, 2018). Because that energy is modulated by cloud microphysical and optical properties, various remote sensing techniques have been developed to estimate these optical properties from satellite (Nakajima and Nakajima 1995; Letu et al. 2019) and ground (Min et al. 2003; Liu et al. 2013) observations. Nevertheless, discrepancies between satellite and surface estimates are frequently reported (e.g., Liu et al. 2013; Khatri et al. 2018).

Algorithms applied to passive satellite sensors typically estimate cloud optical properties using observed reflectance data for water non-absorbing and absorbing wavelengths (e.g., Nakajima and King 1990). Thus, by including ancillary information, cloud optical depth (COD) and cloud-particle effective radius (Re) can be estimated. The optical properties can also be estimated by ground-based observations using zenith radiance (Kikuchi et al. 2006; Liu et al. 2013) or global irradiance (Leontyeva and

Corresponding author: Alessandro Damiani, Center for Environmental Remote Sensing, Chiba University, 1-33 Yayoicho, Inage-ku, Chiba, 2638522, Japan. E-mail: alecarlo.damiani@gmail.com.
Stamnes 1994; Min et al. 2003), or sky camera systems (Mejia et al. 2016; Schwartz et al. 2017). Although the approach based on zenith radiance is considered the standard technique, such measurements are somewhat rare. Therefore, the validation of satellite-based estimates using surface station data is generally based on a limited number of locations, but the reliability of satellite datasets is often affected by the microclimate and morphology of the specific region (Damiani et al. 2013).

In contrast, pyranometers are routinely employed at meteorological stations to record global downwelling horizontal radiation (GHI), at a temporal resolution of 1-300 s, which is higher than those usually employed by most sky radiometers. Sky camera systems, which are also largely used at meteorological stations, are characterized by high temporal resolution and low cost, and can be used to monitor the spatial distribution of radiance (e.g., Saito et al. 2016). With some limitations, COD can be estimated from both pyranometer and camera systems. Therefore, they can potentially integrate dedicated cloud monitoring stations contributing to the validation of satellite data.

An intensive campaign to monitor the atmospheric environment was conducted at the SKYNET (http://atmos3.cr.chiba-u.jp/ skynet/) station of Chiba University (Chiba/Japan) during 1-16 November 2018. Within this framework, we conducted a careful evaluation of four COD datasets retrieved from surface observations of i) zenith radiance data recorded by two sky radiometers based on two independent algorithms, ii) solar radiation data obtained using a pyranometer, and iii) spatial distribution of radiance recorded using a sky camera system equipped with a fisheye lens (Table 1). We then assessed satellite-based COD estimates, obtained from observations by the Advanced Himawari Imager (AHI) aboard Himawari-8 (H-8) and the Second-generation Global Imager (SGLI) on Global Change Observation Mission for Climate (GCOM-C), to explore differences between satellite and ground data in terms of atmospheric conditions, acquisition geometry, and COD spatial distribution. Our objective was to perform an unbiased comparison by explicitly evaluating most of the factors potentially responsible for discrepancies between satellite and surface estimates.

As both satellite sensors became operational only recently, the current literature still lacks an extensive evaluation of their cloud products in comparison with ground-based observations. Therefore, results achieved during this campaign are expected to be of broad interest to the scientific community.

\section{Data and methods}

\subsection{Surface observations and retrieval strategies}

Building on prior efforts (e.g., Kikuchi et al. 2006), COD was computed using observations of zenith radiance with a time resolution of 10 and 15 min that were recorded by two sky radiometers (POM-02, Prede Co., Ltd., Japan) based on two original retrieval strategies. To moderate problems caused by multiple retrieval solutions, both methods were based on transmittance at three wavelengths. 
Table 1. Summary of the observations, retrieval descriptions and references of the datasets used in this study.

\begin{tabular}{|c|c|c|c|c|c|c|c|c|c|}
\hline Platform & Instrument & $\begin{array}{l}\text { Observed } \\
\text { data }\end{array}$ & $\begin{array}{l}\text { Retrieved } \\
\text { parameters }\end{array}$ & Acronym & $\begin{array}{l}\text { COD } \\
\text { wavelength } \\
(\mathrm{nm})\end{array}$ & $\begin{array}{l}\text { Retrieval } \\
\text { wavelengths } \\
(\mathrm{nm})\end{array}$ & Time step & Surface albedo & References \\
\hline surface & skyradiometer & $\begin{array}{l}\text { Zenith } \\
\text { radiance }\end{array}$ & $\mathrm{COD}, \mathrm{Re}$ & $\mathrm{COD}_{(\mathrm{ZEN} 1)}$ & 1020 & $\begin{array}{l}1020,1627 \\
2200\end{array}$ & $15 \mathrm{~min}$ & Fixed at 0.188 & $\begin{array}{l}\text { Kudo et al. } \\
2019\end{array}$ \\
\hline surface & skyradiometer & $\begin{array}{l}\text { Zenith } \\
\text { radiance }\end{array}$ & $\mathrm{COD}, \mathrm{Re}$ & $\mathrm{COD}_{(\mathrm{ZEN} 2)}$ & 550 & $\begin{array}{l}870,1020 \\
1627\end{array}$ & $10 \mathrm{~min}$ & $\begin{array}{l}\text { MODIS MCD43A4 } \\
\text { product }\end{array}$ & $\begin{array}{l}\text { Khatri et al. } \\
\quad 2018\end{array}$ \\
\hline surface & pyranometer & $\begin{array}{l}\text { Global } \\
\text { irradiance }\end{array}$ & COD & $\mathrm{COD}_{(\mathrm{GHI})}$ & $310-2800$ & $310-2800$ & $1 \mathrm{~min}$ & Fixed at 0.15 & $\begin{array}{l}\text { Serrano et al. } \\
\quad 2014\end{array}$ \\
\hline surface & Sky-camera & $\begin{array}{c}\text { Spatial } \\
\text { radiance }\end{array}$ & COD & $\mathrm{COD}_{(\mathrm{CAM})}$ & 550 & VIS & $1 \mathrm{~min}$ & $0.02-0.5$ & $\begin{array}{l}\text { Masuda et al. } \\
2019\end{array}$ \\
\hline H-8 & AHI & $\begin{array}{l}\text { Reflected } \\
\text { radiation }\end{array}$ & $\mathrm{COD}, \mathrm{Re}$ & $\mathrm{COD}_{(\mathrm{AHI})}$ & 640 & $\begin{array}{l}640,2300 \\
10400\end{array}$ & $10 \mathrm{~min}$ & Yoshida et al. 2018 & Letu et al. 2018 \\
\hline GCOM-C & SGLI & $\begin{array}{l}\text { Reflected } \\
\text { radiation }\end{array}$ & COD & $\mathrm{COD}_{\text {(SGLI) }}$ & 1050 & $\begin{array}{l}1050,2210 \\
10800\end{array}$ & overpass & Murakami 2018 & $\underset{2019}{\text { Nakajima et al. }}$ \\
\hline
\end{tabular}

The first cloud retrieval with zenith sky radiances $\left(\mathrm{COD}_{(\mathrm{Zen1})}\right)$ was based on transmittance at wavelengths of 1020, 1627, and $2200 \mathrm{~nm}$ (Kudo et al. 2019). Calibration constants were determined by side-by-side comparison with a reference sky radiometer. In addition to optical depth and effective radius, we estimated both water and ice COD. The Voronoi aggregate particle model (Ishimoto 2012) was used for ice particles. The retrieval adopted an optimal estimation based on the maximum likelihood method and minimized the cost function using the Covariance Matrix Adaptation Evolution Strategy (CMA-ES, Hansen and Ostermeier 2001). The Pstar radiative transfer model (Ota 2010) was used for forward calculations of transmittance from $\mathrm{COD}, \mathrm{Re}$, and the ratio of ice COD.

The second cloud retrieval $\left(\mathrm{COD}_{(\mathrm{Zen2})}\right)$ was based on transmittance at wavelengths of 870, 1020, and $1627 \mathrm{~nm}$ (Khatri et al.

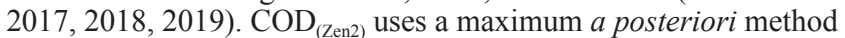
(Rodgers 2000), minimizing the cost function to retrieve COD and Re simultaneously. A novel on-site calibration technique for the $1627 \mathrm{~nm}$ wavelength channel was also developed (Khatri et al. 2017). The SBDART radiative transfer model (Ricchiazzi et al. 1998) was used for forward calculation of transmittance; information on precipitable water vapor content (PWC) and surface albedo was based on observations.

An effective COD can be retrieved by matching observations of global irradiance with simulations including a fixed cloud layer (Serrano et al. 2014). To make this COD comparable with other estimates, only CODs under overcast conditions were selected. We used a CM-21 pyranometer (Kipp and Zonen) that is fully compliant with the World Meteorological Organization (WMO 2014) specifications for high-quality instruments to measure GHI from 310 to $2800 \mathrm{~nm}$. A liquid water cloud layer (1-km base height, 1-km thickness) with a fixed Re of $10 \mu \mathrm{m}$ was included in our one-dimensional (1D) simulations based on the Library for Radiative Transfer using the DISORT solver (Stamnes et al. 1988). We adopted a look-up table approach with constant $\mathrm{O}_{3}$, surface albedo, and aerosol load based on averages of observed data. The temporal resolution of this dataset $\left(\mathrm{COD}_{(\mathrm{GHI})}\right)$ was $1 \mathrm{~min}$.

Based on digital sky images recorded by a previously calibrated sky camera system, we estimated the COD spatial distribution using a deep-learning algorithm based on 3D radiative transfer (Masuda et al. 2019). The angular distribution of visible transmitted radiance training data was generated by simulations using Monte Carlo Atmospheric Radiative Transfer Simulator (MCARaTS), a 3D radiative transfer model (Iwabuchi 2006), assuming various 3D cloud fields obtained from highresolution cloud dynamical simulations. The sky image was cropped, transformed to equidistant projection, and averaged to a size of $128 \times 128$ pixels embracing a field within $45^{\circ}$ of the center. A deep convolutional neural network was trained to estimate COD at every pixel of the input image. The root mean square error (RMSE), evaluated by simulation data, was $48 \%$ for COD $>1$ and higher for COD $<1$, although smaller (around $20 \%$ ) for overcast cloud than for broken clouds. We will discuss the spatial distribution of COD as well as the variability of the average of all pixels $\left(\mathrm{COD}_{(\mathrm{Cam} \text { mean })}\right)$ and the zenith pixels $\left(\mathrm{COD}_{(\mathrm{Cam} \text { zen })}\right)$ within each image. As the sky camera provided slant-column COD along each line of sight, we multiplied COD by the cosine of the viewing zenith angle (VZA) for comparison with other estimates.

Overcast conditions were recognized in digital sky camera images by applying an algorithm based on the red/blue ratio (Long et al. 2006), and evaluated using a more sophisticated algorithm (Saito and Iwabuchi 2016). In this study, we defined overcast conditions as a cloud fraction of $\geq 0.98$. Unless otherwise stated, all subsequent results are reported for overcast conditions.

In the following, the clear sky index (CSI; also cloud modification factor (CMF)) is defined as the ratio of recorded irradiance to the corresponding expected clear sky irradiance under the same conditions (Damiani et al. 2018). We focused our analysis on water clouds identified from satellite observations. To limit ice clouds in our dataset, we restricted the following analysis to data with CSI $<0.8$ (Marin et al. 2018).

\subsection{Satellite-based products}

Satellite data were retrieved from the new H-8 geostationary satellite (Bessho et al. 2016) and the recently launched (23 December 2017) GCOM-C, which is a sunsynchronous quasipolar low Earth orbit satellite. AHI, aboard H-8, is a 16-channel multispectral imager able to capture visible light and infrared images with full-disk observations every $10 \mathrm{~min}$. SGLI (Tanaka et al. 2009; Letu et al. 2016; Nakajima et al. 2019), aboard GCOM-C, is a 19-channel radiometer. Its spatial resolution is $0.5-2 \mathrm{~km}$ for AHI data and $0.25-1 \mathrm{~km}$ for SGLI. Satellite-derived cloud optical properties, particularly Re and COD (subsequently referred to as $\mathrm{COD}_{(\mathrm{AHI})}$ and $\mathrm{COD}_{(\mathrm{SGLI})}$ ), were estimated using the Comprehensive Analysis Program for Cloud Optical Measurement (CAPCOM) algorithm (Nakajima and Nakajima 1995; Kawamoto et al. 2001) for both satellites. The AHI and SGLI-based cloud products used in this study have nominal resolutions of $0.05^{\circ} \times$ $0.05^{\circ}$ and $1 \mathrm{~km} \times 1 \mathrm{~km}$, respectively.

\section{Results}

The distribution of the cloud fraction during the campaign is shown in Fig. 1a. Broken cloud episodes were rare; the sky was dominated by either clear sky or overcast conditions (Fig. 1b). Cloud transmission under overcast conditions was widely distributed, but, in most cases, CSI was $<0.5$. The overall CSI distribu- 

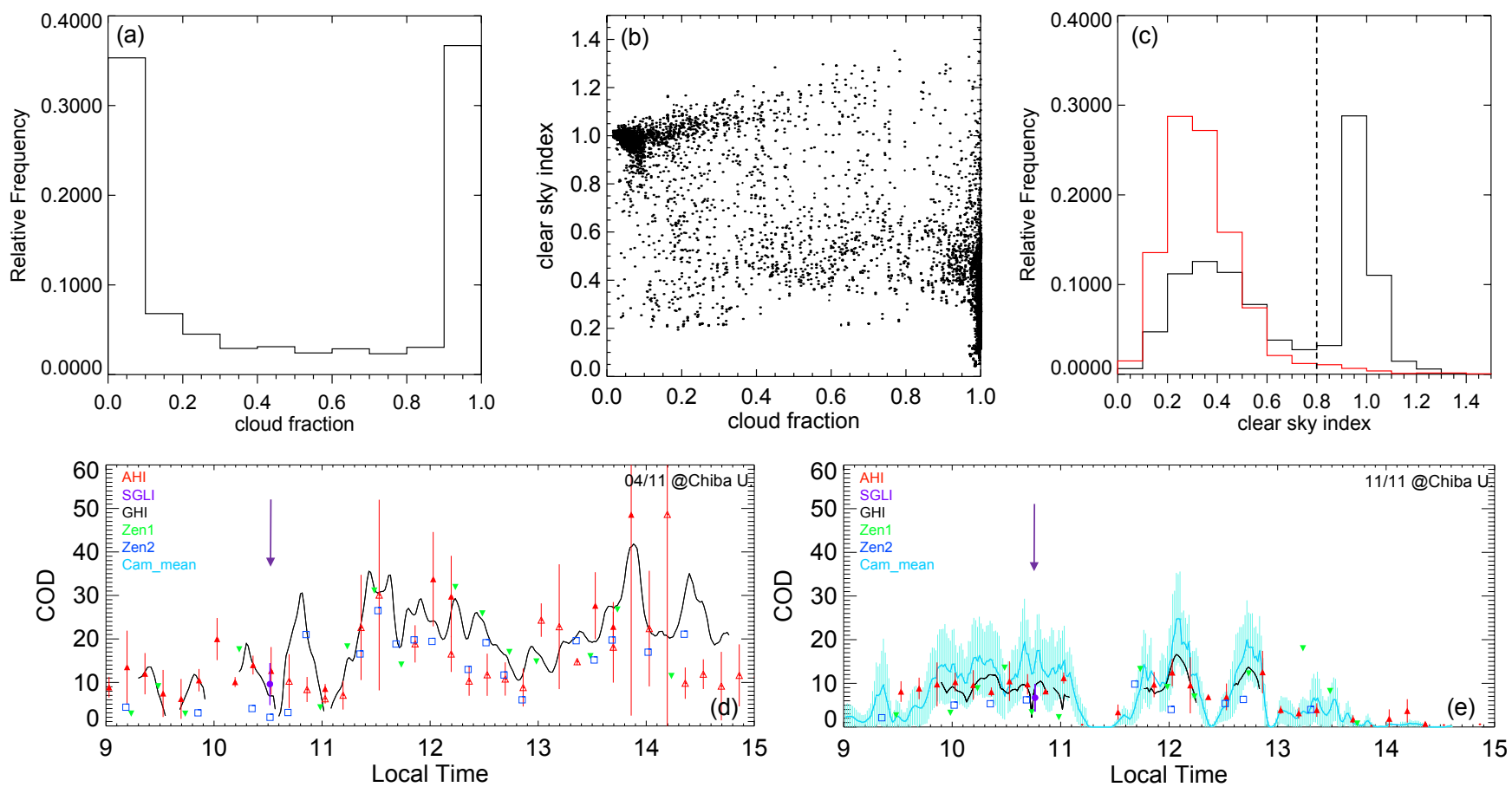

Fig. 1. Top panels: frequency distribution of the cloud fraction (a), scatter plot of cloud fraction and clear sky index (b), and frequency distribution of the clear sky index (c) under all sky (black line) and overcast (red line) conditions during the Chiba campaign period. Bottom panels: time series of the cloud optical depth (COD) datasets at Chiba University for two selected case studies: November 4 (d) and November 11 (e), retrieved from Himawari-8/Advanced Himawari Imager (H-8/AHI; red filled triangles, water clouds; red empty triangles, ice clouds), Global Change Observation Mission for Climate/Secondgeneration Global Imager (GCOM-C/SGLI; violet filled circles), global radiation (black line, only for overcast sky conditions), and zenith radiance (green triangles and blue squares for Zen1 and Zen2, respectively) observations as well as sky camera images (cyan line; average of spatial COD distribution for each image). Satellite pixels were averaged within a distance of $6 \mathrm{~km}$ from the station (see Fig. 3). Vertical bars represent one standard deviation; violet arrow indicates GCOM-C overpass time.

tion showed a double peak, at around 1 and $0.3-0.4$, whereas that under overcast conditions peaked at around $0.2-0.3$ (Fig. 1c).

A time series of COD at Chiba University on two representative days is shown in Fig. 1 (lower panels). Although most of the following discussion will focus on water clouds (as identified by $\mathrm{H}-8 / \mathrm{AHI}$ ), the first case study (November 4, Fig. 1d) was characterized by the presence of both water and ice clouds, as well as persistent overcast conditions and large changes in COD throughout the day. Despite this strong variability, the various surface datasets showed reasonable agreement with each other and with satellite-based COD. Some discrepancies were observed when cloudiness was dominated by ice clouds (e.g., 14:00-15:00), probably because surface retrievals were optimized for water clouds.

In contrast to the previous case study, Fig. 1e focuses on a single day (November 11) that was characterized by a more constant COD and limited periods of overcast conditions. Again, surface COD estimates were generally close to satellite COD, but $\mathrm{COD}_{(\mathrm{Zen} 2)}$ tended to underestimate the other datasets. Figure 1e also includes the time series of average COD spatial distribution retrieved from each sky camera image $\left(\mathrm{COD}_{\left(\mathrm{Cam} \_ \text {mean }\right)}\right)$. $\mathrm{COD}_{\left(\mathrm{Cam} \_ \text {mean) }\right.}$ overestimated the other retrievals under overcast conditions (e.g., around 10:00-11:00 and 12:00), but appeared to be closer under other sky conditions. Despite this overestimation, $\mathrm{COD}_{\text {(Cam mean) }}$ variability appeared to follow $\mathrm{COD}_{(\mathrm{GHI})}$ variability rather than that of the two $\mathrm{COD}_{(\mathrm{Zen})}$ estimates.

The spatial distribution of COD retrieved from the sky camera for November 11 is shown in Fig. 2, including the time evolution of the coefficient of variation (CV) of COD (Fig. 2a) and COD (Fig. 2b), along the VZA. Overcast periods and their associated COD estimates (Fig. 1e) were characterized by low CV, whereas maximum CV was associated with very low COD (e.g., 9:0010:00), which was only partially captured by H-8 observations. $\mathrm{CV}$ exhibited clear VZA dependence such that larger (lower) vari- ation was associated with high (low) VZA (Fig. 2d). In contrast, COD did not show any VZA dependence until about $38^{\circ}$ (Fig. 2e), indicating appropriate vignetting correction. The decrease in COD at larger VZA values suggests that retrieval was not very reliable in that range. The higher correlation of camera-based COD with $\mathrm{COD}_{(\mathrm{GHI})}$ at high VZA values (Fig. 2f) may have occurred because more pixels were used for averaging in that range.

Figure $2 \mathrm{c}$ shows the distribution of COD as retrieved by the ground-based sky camera system superimposed over $\mathrm{COD}_{(\mathrm{SGLI})}$ and $\operatorname{COD}_{(\mathrm{AHI})}$ at 10:46 (local time) on 11 November 2018. Lidar observations showed a cloud base height of about $2 \mathrm{~km}$, so the sky visualized by the camera was restricted to a limited area around the station. In addition to providing a more detailed cloud pattern, $\mathrm{COD}_{(\mathrm{Cam})}$ demonstrates greater variability than $\mathrm{COD}_{\text {(SGLI) }}$, so the latter provides a more uniform spatial distribution, with pixels that smooth the camera-based pattern.

The correlation between surface $\mathrm{COD}$ and satellite $\mathrm{COD}_{(\mathrm{AHI})}$ pixels is shown in Fig. 3a. To obtain an acceptable number of matches between sky radiometer and satellite data, we used a time window of $5 \mathrm{~min}$ for all datasets. The ground station is located exactly between two pixels, and all correlations peaked near pixels $\left(\mathrm{r}=0.81,0.75\right.$, and 0.56 for $\mathrm{COD}_{(\mathrm{GHI})}, \mathrm{COD}_{(\mathrm{Zen} 1)}$, and $\mathrm{COD}_{(\mathrm{Zen} 2)}$, respectively). As expected, the correlation between $\mathrm{COD}_{(\mathrm{AHI})}$ and $\mathrm{COD}_{(\mathrm{GHI})}$ was somewhat uniform over most of the central pixels, whereas those between $\mathrm{COD}_{(\mathrm{AHI})}$ and both $\mathrm{COD}_{(\mathrm{Zen})}$ datasets were noticeable only for the nearest pixels.

The corresponding mean bias between ground and satellite COD datasets is shown in Fig. 3b. Most pixels showed a negative bias, i.e., satellite COD was larger than surface-based estimates by at least $2-3$.

Due to the limited temporal resolution of the sky radiometer, only a small number of matches occurred between the two sky radiometers (Fig. S1a) and between sky-radiometers and satellite within a reasonable time window. Therefore, we compared satel- 

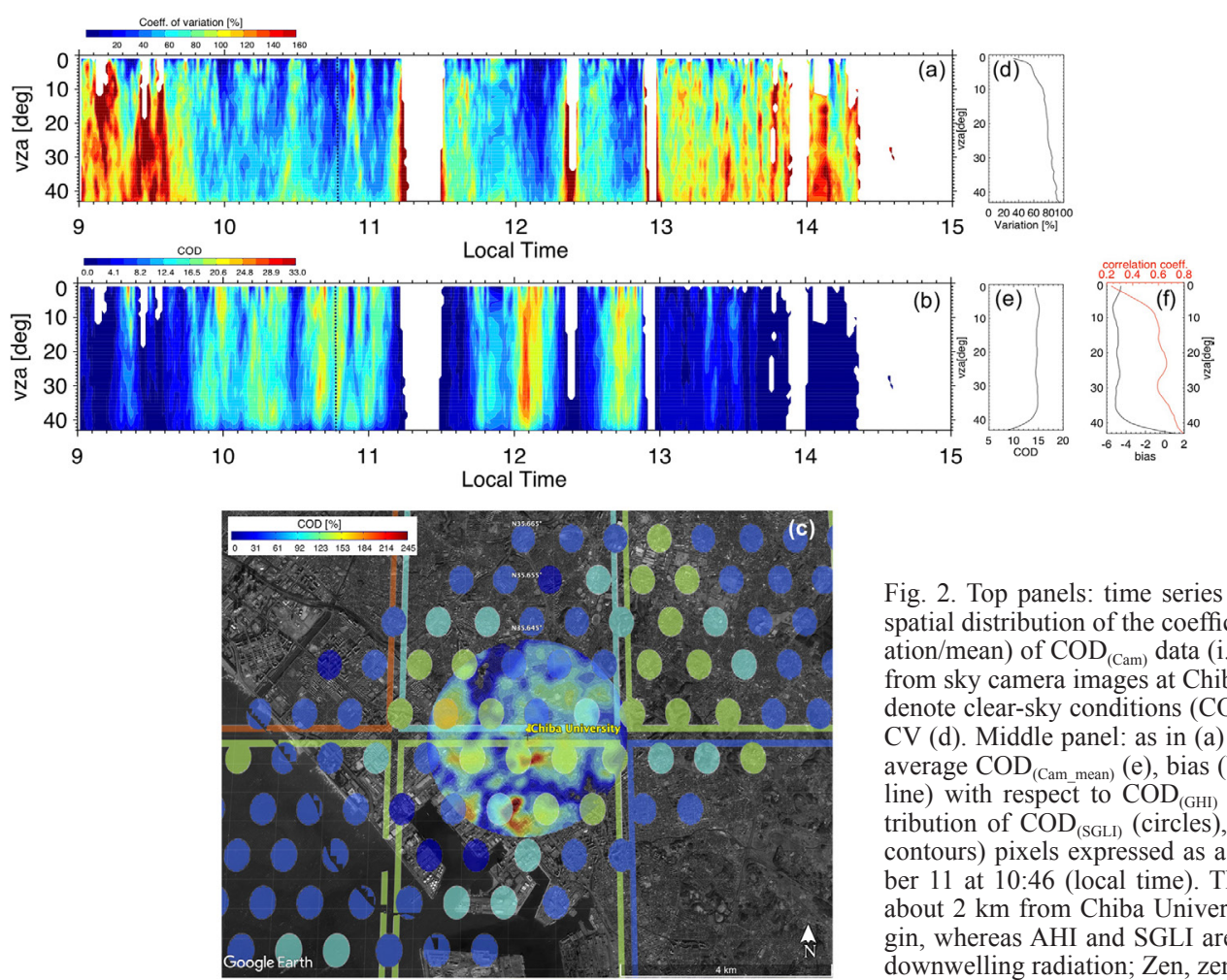

Fig. 2. Top panels: time series along viewing zenith angle (VZA) of the spatial distribution of the coefficient of variation $(\mathrm{CV} ; \mathrm{CV}=$ standard deviation/mean) of $\mathrm{COD}_{(\mathrm{Cam})}$ data (i.e., azimuthally averaged values) estimated from sky camera images at Chiba University on November 11; white areas denote clear-sky conditions $\left(\mathrm{COD}_{(\mathrm{Cam})}<0.2\right)$ (a); right inset: daily average $\mathrm{CV}$ (d). Middle panel: as in (a) except for $\mathrm{COD}_{\text {(Cam) }}$ (b); right insets: daily average $\mathrm{COD}_{\text {(Cam mean) }}(\mathrm{e})$, bias (black line), and correlation coefficient (red line) with respect to $\mathrm{COD}_{(\mathrm{GHI}}$ under overcast conditions (f); spatial distribution of $\mathrm{COD}_{\text {(SGLI) }}$ (circles), $\mathrm{COD}_{\text {(AHI) }}$ (lines), and $\mathrm{COD}_{\text {(Cam_mean) }}$ (filled contours) pixels expressed as a percentage of the zonal mean on November 11 at 10:46 (local time). The $\mathrm{COD}_{(\mathrm{Cam})}$ pattern covers an area within about $2 \mathrm{~km}$ from Chiba University (c). COD subscripts indicate data origin, whereas AHI and SGLI are satellites; Cam, sky camera; GHI, global downwelling radiation; Zen, zenith sky radiance.
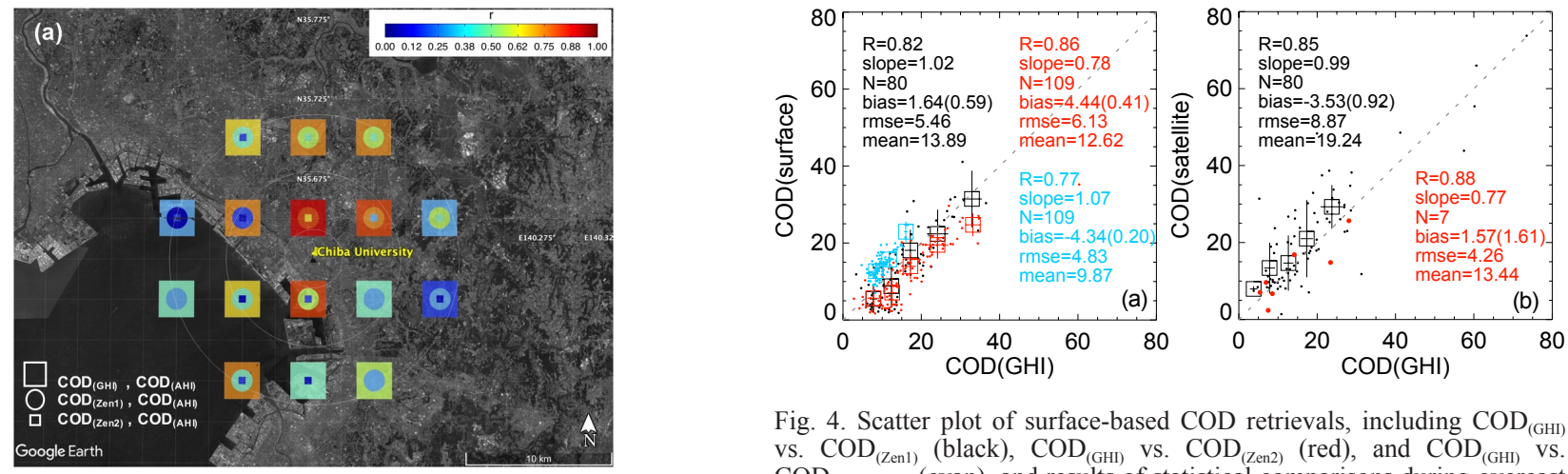

Fig. 4. Scatter plot of surface-based $\mathrm{COD}$ retrievals, including $\mathrm{COD}_{(\mathrm{GHI})}$ vs. $\mathrm{COD}_{\text {(Zen1) }}$ (black), $\mathrm{COD}_{\text {(GHI) }}$ vs. $\mathrm{COD}_{\text {(Zen2) }}$ (red), and $\mathrm{COD}_{(\mathrm{GHI})}$ vs. $\mathrm{COD}_{\text {(Cam_mean) }}$ (cyan), and results of statistical comparisons during overcast conditions at Chiba university within a time window of $1 \mathrm{~min}$ during the campaign period (a); scatter plots as in (a) except for satellite-based COD (AHI, black; SGLI, red) (b). The $\mathrm{COD}_{(\mathrm{GHI})}$ vs. $\mathrm{COD}_{\left(\mathrm{Cam} \_ \text {mean) }\right.}$ comparison was limited to November 11. The 1-sigma error of the mean bias is reported within brackets. Results of the statistical comparisons are summarized in Table 2.

lite $\mathrm{COD}$ to $\mathrm{COD}_{(\mathrm{GHI})}$ with high time resolution, and the accuracy of $\mathrm{COD}_{(\mathrm{GHI})}$ was assessed with available two $\mathrm{COD}_{(\mathrm{Zen})}$. Surface COD estimates and statistical comparisons performed within a time window of 1 min are shown in Fig. 4 a.

Considering the various retrieval approaches and instruments used to obtain the data, these results are satisfactory (Table 2). $\mathrm{COD}_{(\mathrm{GHI})}$ and both $\mathrm{COD}_{(\mathrm{Zen})}$ datasets were well correlated $(\mathrm{r}=0.82$ and 0.86 for $\mathrm{COD}_{(\mathrm{Zen} 1)}$ and $\mathrm{COD}_{(\mathrm{Zen} 2)}$, respectively), and the two sky radiometers performed similarly. Scatter along the 1:1 line was mainly caused by differences between the small field of view (FOV) of the sky radiometer $\left(1^{\circ}\right)$ and the large FOV of the pyranometer. RMSEs of both comparisons were somewhat low (about 5-6), and mean $\mathrm{COD}_{(\text {Zen1) }}$ and $\mathrm{COD}_{(\mathrm{Zen} 2)}$ estimates were also close. The slope of the linear regression line between $\mathrm{COD}_{(\mathrm{GHI})}$ and $\mathrm{COD}_{\text {(Zen1) }}$ retrieval was 1.02 , although a small bias was observed. In contrast, the comparison with $\mathrm{COD}_{(\mathrm{Zen} 2)}$ showed a larger bias. three surface $\mathrm{COD}$ datasets $\left(\mathrm{COD}_{(\mathrm{GH})}, \mathrm{COD}_{(\mathrm{Zen1})}\right.$, and $\mathrm{COD}_{(\mathrm{Zen} 2)}$, indicated by large squares, circles, and small squares, respectively) and satellitebased $\left(\mathrm{COD}_{(\mathrm{AHI}}\right)$ pixels around Chiba University station during the campaign period (a); spatial distribution as in (a) except that mean bias (i.e. surface - satellite) is shown only for significantly correlated datasets $(99 \%$ confidence level; Student's t-test) (b). Comparisons were performed within a time window of $5 \mathrm{~min}$. White circles in (a) and (b) indicate distances of 2, 6, and $10 \mathrm{~km}$ from Chiba University. $\mathrm{COD}_{(\mathrm{GHI})}$ and $\mathrm{COD}_{(\mathrm{Zen1})} \& \mathrm{COD}_{(\mathrm{Zen} 2)}$ were estimated under overcast and all sky conditions, respectively. 
Table 2. Summary of the results of the comparison in Fig. 4. See Table 1 for the explanation of the acronyms. (*only for data of 11 November 2018).

\begin{tabular}{|c|c|c|c|c|c|}
\hline Datasets & $\mathrm{COD}_{(\mathrm{GHI})}, \mathrm{COD}_{(\mathrm{ZEN} 1)}$ & $\mathrm{COD}_{(\mathrm{GHI})}, \mathrm{COD}_{(\mathrm{ZEN} 2)}$ & $\mathrm{COD}_{(\mathrm{GHI})}, \mathrm{COD}_{(\mathrm{CAM})} *$ & $\mathrm{COD}_{(\mathrm{GHI})}, \mathrm{COD}_{(\mathrm{AHI})}$ & $\mathrm{COD}_{(\mathrm{GHI})}, \mathrm{COD}_{(\mathrm{SGLI})}$ \\
\hline Correlation coef. & 0.82 & 0.86 & 0.77 & 0.85 & 0.88 \\
\hline Slope of regres. line & 1.02 & 0.78 & 1.07 & 0.99 & 0.77 \\
\hline Number of samples & 80 & 109 & 109 & 80 & 7 \\
\hline Mean bias \pm 1 -sigma & $1.64 \pm 0.59$ & $4.44 \pm 0.41$ & $-4.34 \pm 0.20$ & $-3.53 \pm 0.92$ & $1.57 \pm 1.61$ \\
\hline RMSE & 5.46 & 6.13 & 4.83 & 8.87 & 4.26 \\
\hline
\end{tabular}
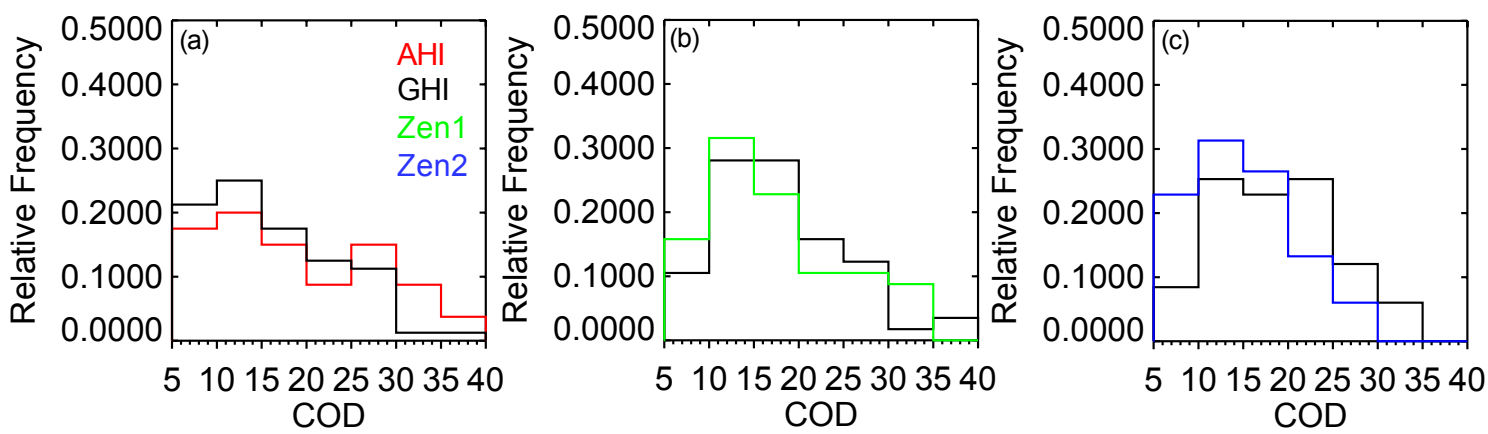

Fig. 5. Frequency distribution of COD within the range 5-40 obtained from the datasets compared in Fig. 4 : $\mathrm{COD}_{(\mathrm{AHI})}(\mathrm{red})$ and $\mathrm{COD}$ (GHI) $(\mathrm{black})(\mathrm{a})$, $\mathrm{COD}_{(\mathrm{Zen} 1)}$ (green) and $\mathrm{COD}_{(\mathrm{GHI})}(\mathrm{b})$, and $\mathrm{COD}_{(\mathrm{Zen} 2)}$ (blue) and $\mathrm{COD}_{(\mathrm{GHI})}(\mathrm{c})$.

Thus, $\mathrm{COD}_{(\mathrm{Zen} 2)}$ was biased with respect to $\mathrm{COD}_{(\mathrm{Zen} 1)}$, by about $2-3$. Similar conclusions can be drawn by directly comparing the two sky radiometer estimates under all sky conditions and within a larger time window (Fig. S1a).

Although limited to November 11, Fig. 4a also compares $\mathrm{COD}_{(\mathrm{GHI})}$ and $\mathrm{COD}_{\left(\mathrm{Cam} \_ \text {mean) }\right.}$ (see also Fig. 1e). There was sufficient correlation between the two datasets $(r=0.77)$, and RMSE was similar to that reported above. Nevertheless, camera-based COD was positively biased. This overestimation was confirmed by comparing image-based $\mathrm{COD}_{(\mathrm{Cam} \text { zen) }}$ with $\mathrm{COD}_{\text {(Zen1) }}$ (Fig. S1b).

An evaluation of satellite COD products is shown in Fig. 4b. In this analysis, we compared $\mathrm{COD}_{(\mathrm{GHI})}$ with the average of satellite pixels within a distance of $6 \mathrm{~km}$ from Chiba station (see Fig. $3 a)$. The H-8/AHI correlation $(r=0.85)$ was virtually identical to that achieved using co-located instruments; the slope of the linear regression line was 0.99 . In contrast, we observed negative bias $(-3.51)$, as $\mathrm{COD}_{(\mathrm{AHI})}$ exceeded $\mathrm{COD}_{(\mathrm{GHI})}$ (see also Fig. 3b). For completeness, we show a similar analysis for GCOM-C/SGLI data in Fig. 4b. Although the correlation $(\mathrm{r}=0.88)$ suggests adequate accuracy of the satellite COD estimates, the limited number of samples prevents us from drawing any definitive conclusions.

The relative frequency distribution of COD in the common range 5-40 is shown in Fig. 5. In surface-based datasets, frequency generally decreased as COD increased, with a mode around 1015. This result was confirmed by the AHI estimates. However, $\mathrm{COD}_{(\mathrm{GHI})}$ tended to underestimate the distribution of low COD (roughly $<20$ ) and overestimate that of high COD $(>20)$ when compared with both $\mathrm{COD}_{(\mathrm{Zen})}$ distributions; the opposite trend was observed when $\mathrm{COD}_{(\mathrm{GHI})}$ and $\mathrm{COD}_{(\mathrm{AHI})}$ were compared, with $\mathrm{COD}_{(\mathrm{AHI})}$ tending to underestimate (overestimate) the distribution of $\mathrm{COD}_{(\mathrm{GHI})}$ among low (high) COD values.

Previous studies have shown that the assumption of fixed $\mathrm{Re}$ during retrieval has little impact on the resulting $\mathrm{COD}_{(\mathrm{GHI})}$ (e.g., Khatri et al. 2018). In this study, we assumed $\mathrm{Re}=10 \mu \mathrm{m}$, which is the typical value for overcast conditions. Indeed, the mode of the $\mathrm{AHI} / \mathrm{H}-8 \mathrm{Re}$ distribution was around $13 \mu \mathrm{m}$, although both zenith radiance datasets showed somewhat smaller values (Fig. S2).

\section{Discussion and conclusion}

Focusing on overcast conditions, we evaluated various COD datasets retrieved from surface observations of zenith radiance, solar radiation, and spatial distribution of radiance. Overall, there was good agreement among all surface datasets, which described a common temporal path. We found satisfactory correlations between $\mathrm{COD}_{(\mathrm{GHI})}$ and both $\mathrm{COD}_{(\mathrm{Zen})}$ datasets, with values generally distributed close to the 1:1 line and small RMSE and bias. Some discrepancies were likely caused by the different FOV of the two instruments, possible multi-solution $\mathrm{COD}_{(\mathrm{Znn})}$ issues as well as other factors discussed in Supplementary Material 2. COD retrieved from a sky camera system resulted in positive bias relative to the other surface datasets; however, a sufficiently high correlation was observed. Overall, we conclude that $\mathrm{COD}_{\text {(Cam mean) }}$ $>\mathrm{COD}_{(\mathrm{GHI})}>\mathrm{COD}_{(\mathrm{Zen1})}>\mathrm{COD}_{(\mathrm{Zen2})}$. We suggest broader use of the pyranometer and the camera-based approach when dedicated cloud property observations are not available.

We also assessed satellite-based COD estimates retrieved from H-8/AHI and GCOM-C/SGLI observations. The correlation and slope of the linear regression line obtained using AHI data were virtually identical to those achieved using adjacent instruments. However, this comparison yielded a small positive bias with respect to surface estimates.

\section{Acknowledgments}

This study was supported by the JST CREST grant number JPMJCR15K4. P.K. was supported by JSPS Grant-in-aid for scientific research (c) number 17K05650.

Edited by: K. Kawamoto

\section{Supplementary Material 1}

Figure S1. Scatter plot of the two sky radiometer-based COD datasets (Zen1 and Zen2) and results of statistical comparison performed within a time window of 5 min during the campaign period (a); scatter plot of sky radiometer-based $\operatorname{COD}_{(\text {Znen), as }}$ well as camera-based $\mathrm{COD}_{(\mathrm{Cam} \text { zen) }}$, averaging pixels with VZA $<$ $0.55^{\circ}$, and results of statistical comparison performed within a time window of $1 \mathrm{~min}$ for 11 November 2018 (b); scatter plot of camera-based $\mathrm{COD}_{(\mathrm{Cam} \text { mean) }}$ and $\mathrm{COD}_{(\mathrm{Cam} \text { zen) }}$, as well as results of statistical comparison performed within a time window of $1 \mathrm{~min}$ for 11 November 2018 (c). 
Figure S2. Frequency distribution of cloud particle effective radius $(\mathrm{Re})$ during the campaign period as estimated from groundbased sky radiometers (Zen1 and Zen2) and H-8/AHI observations recorded within a time window of $5 \mathrm{~min}$.

\section{Supplementary Material 2}

\section{Potential reasons for the COD discrepancy within ground-based retrievals}

Several factors can contribute to the small COD discrepancy within ground-based retrievals shown in Fig. 4a. We shortly faced the main issues in the supplement while we leave the specific analysis for future works.

\section{References}

Bessho, K., K. Date, M. Hayashi, A. Ikeda, T. Imai, H. Inoue, Y. Kumagai, T. Miyakawa, H. Murata, T. Ohno, A. Okuyama, R. Oyama, Y. Sasaki, Y. Shimazu, K. Shimoji, and Y. Sumida, 2016: An Introduction to Himawari-8/9 - Japan's new-generation geostationary meteorological satellites. $J$. Meteor. Soc. Japan, 94, 151-183.

Damiani, A., S. Cabrera, R. Muñoz, R. R. Cordero, and F. Labbe, 2013: Satellite-derived UV irradiance for a region with complex morphology and meteorology: Comparison against ground measurements in Santiago de Chile. Int. J. Remote Sens., 34, 5812-5833, doi:10.1080/01431161.2013.796101.

Damiani, A., H. Irie, T. Horio, T. Takamura, P. Khatri, H. Takenaka, T. Nagao, T. Y. Nakajima, and R. R. Cordero R., 2018: Evaluation of Himawari-8 surface downwelling solar radiation by ground-based measurements. Atmos. Meas. Tech., 11, 2501-2521.

Ishimoto, H., K. Masuda, Y. Mano, N. Orikasa, and A. Uchiyama, 2012: Irregularly shaped ice aggregates in optical modeling of convectively generated ice clouds. J. Quant. Spectrosc. Radiat. Transfer, 113, 632-643.

Iwabuchi, H., 2006: Efficient Monte Carlo Methods for radiative transfer modeling. J. Atmos. Sci., 63, 2324-2339.

Kawamoto, K., T. Nakajima, and T. Y. Nakajima, 2001: A global determination of cloud microphysics with AVHRR remote sensing. J. Climate, 14, 2054-2068.

Khatri, P., T. Hayasaka, H. Iwabuchi, T. Takamura, H. Irie, T. Y. Nakajima, H. Letu, and Q. Kai, 2017: Cloud parameters from zenith transmittances measured by sky radiometer at the surface: Method development and satellite product validation. Proc. 19th EGU General Assembly, Vienna, Austria, EGU2017-6727.

Khatri, P., T. Hayasaka, H. Iwabuchi, T. Takamura, H. Irie, T. Y. Nakajima, H. Letu, and Q. Kai, 2018: Validation of MODIS and AHI observed water cloud properties using surface radiation data. J. Meteor. Soc. Japan, 96B, 151-172.

Khatri, P., H. Iwabuchi, T. Hayasaka, H. Irie, T. Takamura, A. Yamazaki, A. Damiani, H. Letu, and Q. Kai, 2019: Retrieval of cloud properties from sky radiometer observed spectral zenith radiances. Atmos. Meas. Tech. Discuss., doi:10.5194/ amt-2019-273.

Kikuchi, N., T. Nakajima, H. Kumagai, H. Kuroiwa, A. Kamei, R. Nakamura, and T. Y. Nakajima, 2006: Cloud optical thickness and effective particle radius derived from transmitted solar radiation measurements: Comparison with cloud radar observations. J. Geophys. Res., 111, D07205, doi:10.1029/ 2005JD006363.

Kudo, R., H. Iwabuchi, T. Takano, H. Irie, A. Damiani, and P. Khatri, 2019: Remote sensing of the cloud physical and optical properties by the sky radiometer. Proc. Meteor. Soc. Japan, 2019 Spring Meeting, 115, 53 (in Japanese).

Leontyeva, E., and K. Stamnes, 1994: Estimations of cloud optical thickness from ground-based measurements of incoming solar radiation in the arctic. $J$. Climate, 7, 566-578.

Liu, J., Z. Li, Y. Zheng, J. C. Chiu, F. Zhao, M. Cadeddu, F. Weng, and M. Cribb, 2013: Cloud optical and microphysical properties derived from ground-based and satellite sensors over a site in the Yangtze Delta region. J. Geophys. Res. Atmos., 118, 9141-9152, doi:10.1002/jgrd.50648.

Letu, H., and co-authors, 2016: Investigation of ice particle habits to be used for ice cloud remote sensing for the GCOM-C satellite mission. Atmos. Chem. Phys., 16, 12287-12303.

Letu, H., T. M. Nagao, T. Y. Nakajima, J. Riedi, H. Ishimoto, A. J. Baran, H. Shang, M. Sekiguchi, and M. Kikuchi, 2019: Ice cloud properties from Himawari-8/AHI next-generation geostationary satellite: Capability of the AHI to monitor the DC cloud generation process. IEEE Trans. Geosci. Remote Sens., 57, 3229-3239.

Long, C. N., J. M. Sabburg, J. Calbó, and D. Pagès, 2006: Retrieving cloud characteristics from ground-based daytime color all-sky images. J. Atmos. Oceanic Technol., 23, 633-652.

Marín, M. J., D. Serrano, M. P. Utrillas, M. Núñez, and J. A. Martínez-Lozano, 2017: Effective cloud optical depth and enhancement effects for broken liquid water clouds in Valencia (Spain). Atmos. Res., 195, 1-8.

Masuda, R., H. Iwabuchi, K. S. Schmidt, A. Damiani, and R. Kudo, 2019: Retrieval of cloud optical thickness from skyview camera images using a deep convolutional neural network based on three-dimensional radiative transfer. Remote Sens., 11, 1962, https://doi.org/10.3390/rs11171962, 2019.

Mejia, F. A., B. Kurtz, K. Murray, L. M. Hinkelman, M. Sengupta, Y. Xie, and J. Kleiss1, 2016: Coupling sky images with radiative transfer models: a new method to estimate cloud optical depth. Atmos. Meas. Tech., 9, 4151-4165.

Min, Q., M. Duan, and R. Marchand, 2003: Validation of surface retrieved cloud optical properties with in situ measurements at the Atmospheric Radiation Measurement Program (ARM) South Great Plains site. J. Geophys. Res. Atmos., 108, 4547, doi:10.1029/2003JD003385.

Murakami, H., 2018: ATBD of GCOM-C/SGLI land amospheric correction algorithm (Oct. 2018, v1.000). Accessed 13 June 2019, https://suzaku.eorc.jaxa.jp/GCOM_C/data/files/SGLI_ Atmcorr_ATBD_v10.pdf.

Nakajima, T., and M. D. King, 1990: Determination of the optical thickness and effective particle radius of clouds from reflected solar radiation measurements. Part I: Theory. $J$. Atmos. Sci., 47, 1878-1893.

Nakajima, T. Y., and T. Nakajima, 1995: Wide-area determination of cloud microphysical properties from NOAA AVHRR measurements for FIRE and ASTEX regions. J. Atmos. Sci., 52, 4043-4059.

Nakajima, T. Y., H. Ishida, T. M. Nagao, M. Hori, H. Letu, R. Higuchi, N. Tamaru, N. Imoto, and A. Yamazaki, 2019: Theoretical basis of the algorithms and early phase results of the GCOM-C (Shikisai) SGLI cloud products. Prog. Earth Planet. Sci., doi:10.1186/s40645-019-0295-9.

Nikolaus, H., and A. Ostermeier, 2001: Completely derandomized self-adaptation in evolution strategies. Evolut. Comput., 9, 159-195.

Ota, Y., A. Higurashi, T. Nakajima, and T. Yokota, 2010: Matrix formulations of radiative transfer including the polarization effect in a coupled atmosphere-ocean system. J. Quant. Spectrosc. Radiat. Transf., 111, 878-894.

Ricchiazzi, P., S. Yang, C. Gautier, and D. Sowle, 1998: SBDART: A research and teaching software tool for plane-parallel radiative transfer in the Earth's atmosphere. Bull. Amer. Meteor. Soc., 79, 2101-2114.

Rodgers, C. D., 2000: Inverse Methods for Atmospheric Sounding, World Scientific, $238 \mathrm{pp}$.

Saito, M., H. Iwabuchi, and I. Murata, 2016: Estimation of spectral distribution of sky radiance using a commercial digital camera. Appl. Opt., 55, 415-424.

Saito, M., and H. Iwabuchi, 2016: Cloud discrimination from sky images based on a clear-sky index. J. Atmos. Oceanic Technol., 33, 1583-1595.

Serrano, D., M. Nunez, M. P. Utrillas, M. J. Marın, C. Marcos, and J. A. Martınez-Lozano, 2014: Effective cloud optical 
depth for overcast conditions determined with a UV radiometers. Int. J. Climatol., 34, 3939-3952.

Schwartz, S. E., D. Huang, and D. V. Vladutescu, 2017: Highresolution photography of clouds from the surface: Retrieval of optical depth of thin clouds down to centimeter scales. J. Geophys. Res. Atmos., 122, 2898-2928, doi:10.1002/ 2016JD025384.

Stamnes, K., S.-C. Tsay, W. Wiscombe, and K. Jayaweera, 1998: Numerically stable algorithm for discrete-ordinate-method radiative transfer in multiple scattering and emitting layered media. Appl. Opt., 27, 2502-2509.

Tanaka, K., Y. Okamura, T. Amano, M. Hiramatsu, and K. Shiratama, 2009: Development status of the second-generation global imager (SGLI) on GCOM-C. Sensors, Systems, and Next-Generation Satellites XIII: Proc. SPIE, Vol. 7474, International Society for Optics and Photonics.

Wild, M., H. Gilgen, A. Roesch, A. Ohmura, C. N. Long, E. G. Dutton, B. Forgan, A. Kallis, V. Russak, and A. Tsvetkov, 2005: From dimming to brightening: Decadal changes in solar radiation at earth's surface. Science, 308, 847-850, doi:10.1126/science.1103215.

Wild, M., M. Z. Hakuba, D. Folini, and co-authors, 2018: The cloud-free global energy balance and inferred cloud radiative effects: An assessment based on direct observations and climate models. Climate Dyn., 52, 4787-4812.

WMO, 2014: Guide to Meteorological Instruments and Methods of Observation, 8th Edition.

Yoshida, M., M. Kikuchi, T. M. Nagao, H. Murakami, T. Nomaki, and A. Higurashi, 2018: Common retrieval of aerosol properties for imaging satellite sensors. J. Meteor. Soc. Japan, 96B, 193-209.

Yoshifumi, O., A. Higurashi, T. Nakajima, and T. Yokota, 2010: Matrix formulations of radiative transfer including the polarization effect in a coupled atmosphere-ocean system. $J$. Quant. Spectrosc. Radiat. Transf., 111, 878-894.

Manuscript received 13 June 2019, accepted 6 August 2019 SOLA: https://www.jstage.jst.go.jp/browse/solal 